(c) American Dairy Science Association, 2006.

\title{
Strategies to Improve the Therapy of Retained Fetal Membranes in Dairy Cows
}

\author{
M. Drillich, ${ }^{1}$ M. Mahlstedt, U. Reichert, B. A. Tenhagen, and W. Heuwieser \\ Clinic for Reproduction, Faculty of Veterinary Medicine, Free University of Berlin, \\ Königsweg 65, 14163 Berlin, Germany
}

\begin{abstract}
In this field trial, a protocol for the treatment of retained fetal membranes (RFM) without any intrauterine therapy was compared with 3 protocols based on the intrauterine use of antibiotic pills (AP), the manual removal (MR) of the fetal membranes, or the combination of both (PR). The study was conducted on 5 commercial dairy farms in Germany. Cows with RFM for at least $24 \mathrm{~h}$ after calving were assigned to 1 of 4 treatment groups. Cows of all groups with a rectal temperature $\geq 39.5^{\circ} \mathrm{C}$ received a systemic antibiotic treatment with ceftiofur ( $1 \mathrm{mg} / \mathrm{kg}$ per d) for 3 to 5 consecutive days. In case of continued fever after 5 treatments, cows received a different antibiotic as an escape therapy. In the reference group (REF; $n=131$ ), cows did not receive any additional treatment. All cows in group AP $(n=119)$ received intrauterine treatment with antibiotic pills consisting of $1,000 \mathrm{mg}$ of ampicillin and $1,000 \mathrm{mg}$ of cloxacillin for 3 consecutive days. In group MR $(n=121)$, an attempt was made to remove the fetal membranes manually, but uterine pills were not administered. In group PR $(\mathrm{n}=130)$, an attempt was made to remove the fetal membranes manually and all cows received a local antibiotic treatment as in group AP. All cows received 2 doses of $25 \mathrm{mg}$ of $\mathrm{PGF}_{2 \alpha}$ : one dose between 18 and $24 \mathrm{~d}$ and another between 32 and $38 \mathrm{~d}$ postpartum. Statistical analyses were performed using binary logistic regression models and survival analyses with group $\mathrm{REF}$ as reference. Of all animals, $79.8 \%$ had a body temperature of $\geq 39.5^{\circ} \mathrm{C}$ at least once within $10 \mathrm{~d}$ postpartum and were treated with ceftiofur. Occurrence of fever within $10 \mathrm{~d}$ postpartum was significantly lower in groups AP and PR compared with reference group REF, but was not different between groups MR and REF. Risk of receiving an escape therapy in case of fever after 5 treatments with ceftiofur did not differ among groups. Reproductive performance measures did not differ significantly between group REF and any of
\end{abstract}

Received April 28, 2005.

Accepted September 29, 2005.

${ }^{1}$ Corresponding author: author@bestandsbetreuung.de the comparison groups. Compared with a treatment protocol based only on systemic treatment with antibiotics for cows with a fever, neither intrauterine antibiotics nor manual removal of fetal membranes alone or in combination reduced proportions of cows needing an escape therapy nor did those treatments improve reproductive measures in the current lactation. Systemic treatment alone based on elevated rectal temperature was effective and reduced use of antibiotics compared with therapies that included intrauterine antibiotics.

Key words: retained fetal membrane, antibiotic treatment, manual removal, dairy cow

\section{INTRODUCTION}

The retention of the fetal membranes (RFM) is defined as the failure to expel the fetal membranes within 12 to $24 \mathrm{~h}$ after calving (Fourichon et al., 2000). Average incidence of RFM ranges from 4 to $11 \%$ of calvings (Eiler, 1997). Many cows with RFM have elevated body temperature as a sign of acute metritis. For dairy cows with RFM, the incidence of fever $\left(\geq 39.5^{\circ} \mathrm{C}\right)$ varies between 36 and 95\% (Dinsmore et al., 1996; Drillich et al., 2003). A meta-analysis by Fourichon et al. (2000) of several publications revealed a negative impact of RFM on reproductive performance of affected cows in the current lactation. However, the results of the evaluated studies were heterogeneous (Fourichon et al., 2000). The frequent occurrence of metritis after RFM was identified as the main reason for reduced fertility of cows with RFM (Laven and Peters, 1996; Gröhn and Rajala-Schultz, 2000).

The therapy of RFM in cattle has been a controversial subject for many years. Manual removal of the RFM and an intrauterine antibiotic treatment are common in veterinary practice in Europe (Laven, 1995) and, to a lesser extent, in the United States and Canada. Some studies have shown that the intrauterine manipulation decreases uterine defense mechanisms (Paisley et al., 1986; Peters and Laven, 1996) and impairs subsequent fertility (Bolinder et al., 1988). However, in a retrospective study on 1,702 cows with RFM, Dyrendahl et al. (1977) showed some positive effects of the manual removal of the retained placenta on reproductive perfor- 
mance. The efficacy of intrauterine administration of antibiotics has been questioned because of multiple interactions of the antibiotic substances with uterine contents and varying degrees of absorption (Paisley et al., 1986; Eiler, 1997). Therefore, overdosing (i.e., extralabel drug use) is frequently practiced in the field to reach effective concentrations of antibiotics in uterine tissue. It has been demonstrated that there is a high risk for residues in milk with extra-label use of administration (Dinsmore et al., 1996).

For cows with acute metritis, often associated with RFM, a systemic antibiotic treatment is recommended by Zhou et al. (2001) and Sheldon and Dobson (2004). Okker et al. (2002) have demonstrated that subcutaneous administration of $1 \mathrm{mg}$ of ceftiofur/ $\mathrm{kg}$ of BW results in concentrations of ceftiofur derivates in uterine tissues and lochial fluids that exceed the reported MIC for the common pathogens; for example, Escherichia coli and Fusobacterium necrophorum. The MIC values assumed by Okker et al. (2002) were confirmed recently by Sheldon et al. (2004) who determined the MIC values of ceftiofur and other antimicrobial drugs against bacteria that cause uterine infections. The clinical efficacy of a systemic antibiotic treatment with ceftiofur in cows with acute metritis has been evaluated in several studies (Smith et al., 1998; Drillich et al., 2001; Zhou et al., 2001; Chenault et al., 2004), but there are only few studies on cows with RFM (Drillich et al., 2003; Risco and Hernandez, 2003). Drillich et al. (2003) demonstrated that a systemic application of ceftiofur $(1 \mathrm{mg} /$ $\mathrm{kg}$ of BW) without manual removal of RFM results in a similar treatment efficacy and reproductive performance compared with conventional intervention; that is, manual removal of the retained placenta and application of local antibiotics. However, in that study, there were only 35 cows per group and the design did not allow for separation of effects of local antibiotic treatment vs. effects of manual removal of the placenta on the treatment outcome.

The objective of the current study was to test the hypothesis that a systemic antibiotic treatment of cows with RFM with ceftiofur only in case of fever and without any local therapy is at least as efficacious as a strategy based on the additional manual removal or the application of uterine antibiotic pills, or both. The verification of this hypothesis would support efforts to reduce the amount of antibiotics used in the field and help to implement the guidelines for prudent use of antibiotics in cattle.

\section{MATERIALS AND METHODS}

The study was conducted in 5 commercial dairy herds in Germany from June 2002 to February 2004. All par- ticipating farmers and veterinarians were informed about relevant characteristics of the study and agreed with the study design. On each participating farm, between 780 and 1,570 Holstein cows were housed in freestall barns with slotted floors and cubicles. At least 1 wk before expected calving, cows were moved into a free-stall barn with straw bedding. The cows were fed a TMR on each farm and milked 3 times daily. Herd average milk yield was between 9,400 and $10,800 \mathrm{~kg}$ per lactation.

Primiparous as well as multiparous cows that retained their placenta for at least $24 \mathrm{~h}$ after calving were included in the study. Cows eligible for the study were assigned on each farm in an alternating order to 1 of the 4 treatment groups. Decisions about enrollment of cows into the study were made in the morning. Therefore, the day of enrollment was d 1 or 2 postpartum, depending on the time of calving. If 2 or more cows with RFM had calved on the same day, the cow with the lowest ear-tag number was examined first and enrolled according to the enrollment scheme before the next cow was examined. Cows undergoing a caesarean section and cows that were not supposed to be bred after calving were not included in the study. All cows that received anti-inflammatory or systemic antibiotic drugs within $10 \mathrm{~d}$ postpartum (PP) for purposes not related to the study (e.g., acute mastitis) were excluded from the trial.

During the first $10 \mathrm{~d}$ PP, rectal body temperature was measured daily in all cows enrolled in the study. In all treatment groups, all cows with a body temperature $\geq 39.5^{\circ} \mathrm{C}$ (i.e., fever) within the first $10 \mathrm{~d}$ PP received a systemic antibiotic treatment consisting of $1 \mathrm{mg}$ of ceftiofur/kg of BW (Excenel RTU, Pfizer Animal Health, Karlsruhe, Germany) applied subcutaneously for 3 consecutive days. Cows with fever for more than $3 \mathrm{~d}$ received ceftiofur $(1 \mathrm{mg} / \mathrm{kg})$ for another $2 \mathrm{~d}$. In case of fever after $5 \mathrm{~d}$ of treatment with ceftiofur, cows were regarded as treatment failures and received an escape therapy chosen by the local veterinarian.

In reference (REF) group, the only therapy applied was the systemic antibiotic treatment with ceftiofur in case of fever. Cows without fever in the REF group did not receive any antibiotic treatment. No attempt was made to remove the fetal membranes and no intrauterine antibiotic pills were administered.

All cows in the antibiotic pills (AP) treatment group received an intrauterine treatment with 2 antibiotic pills with $500 \mathrm{mg}$ of ampicillin and $500 \mathrm{mg}$ of cloxacillin per pill (Aniclox, Animedica, Horb, Germany) for 3 consecutive days, beginning at the day of enrollment. No attempt was made to remove the fetal membranes manually.

In the manual removal (MR) treatment group, an attempt was made, on the day of enrollment, to remove 
the fetal membranes manually for a maximum of 10 min. If unsuccessful, the attempt was repeated on each of the next $2 \mathrm{~d}$. Uterine pills were not administered in this group.

In the combination (PR) treatment group, all cows received an intrauterine treatment with 2 antibiotic pills as in group AP. In addition, an attempt was made to remove the retained placenta as described for group MR. If necessary the attempt was repeated on each of the next $2 \mathrm{~d}$.

All cows enrolled in the study were treated with 25 mg of $\mathrm{PGF}_{2 \alpha}$ intramuscularly (Dinolytic, Pfizer Animal Health) between 18 and $24 \mathrm{~d} \mathrm{PP}$ and again between 32 and 38 d PP. All diagnoses and treatments were documented on case report forms and monitored regularly for each cow. The case report forms remained on farm to assure that all cows received the correct treatments on subsequent days. At the end of the study, case report forms were checked for compliance. Cows with incomplete treatments were retrospectively withdrawn from the study.

The voluntary waiting period varied among the herds from 40 to $50 \mathrm{~d}$ PP. In all herds, cows were bred on observed estrus. No timed breeding protocols (e.g., targeted breeding or Ovsynch) were used. Cows not pregnant after breeding and cows not observed in estrus within $30 \mathrm{~d}$ after the end of the voluntary waiting period were examined by rectal palpation by a veterinarian. Cows with a palpable corpus luteum received $\mathrm{PGF}_{2 \alpha}$ to induce estrus. Other findings (e.g., cystic ovaries) were treated according to the diagnosis.

All cows included in the study were followed up for $200 \mathrm{~d}$ PP. The reproductive performance variables monitored and documented were: days to first service for inseminated cows, days to pregnancy for pregnant cows, first-service conception rate, total conception rate (number of cows pregnant by total number of inseminations), cows pregnant, and cows culled within $200 \mathrm{~d}$ PP. Cows not pregnant within $200 \mathrm{~d}$ PP were regarded as open, even if they remained in the herd and got pregnant later in lactation.

\section{Statistical Analyses}

Data were analyzed using SPSS for Windows (Version 12.0, SPSS Inc., Munich, Germany). Binary logistic regression models were calculated for the risk of receiving an escape therapy and for the risk of conception after first service as outcome variables. The risk of receiving an escape therapy was calculated only for cows with fever within $10 \mathrm{~d}$ PP. Survival analyses for the hazard of fever within $10 \mathrm{~d} \mathrm{PP}$, and the hazards of insemination, pregnancy, and culling within $200 \mathrm{~d} P \mathrm{P}$, respectively were performed using Cox-Regression. For logistic regression models as well as for survival analyses, treatment group (REF, AP, MR, and PR), herd (1 to 5$)$, and parity class ( $0=$ multiparous; $1=$ primiparous), and fever ( $0=$ no; 1 = yes $)$ were included as covariates. Adjusted odds ratios, hazard ratios, confidence intervals, and $P$-values are reported. Fever was not included as covariate in the models for the first day of fever. For all logistic regression models and survival analyses, group REF was the reference group. The reference herd for covariate "herd" was chosen for each analysis with regard to the practical relevance of the data for the farmer; that is, the herd with the numerically best value for each variable was chosen as reference herd.

For logistic regression as well as for survival analyses, confidence interval was set at $95 \%$ and level of significance at $\alpha=0.05$.

\section{RESULTS}

A total of 563 cows were initially enrolled in the study. Sixty-two cows (11.0\%) were not treated according to the study protocol, treated with antibiotics for other than study purposes, or the data were not documented consistently. Those cows were withdrawn from the analyses $(12,21,21$, and 8 cows in groups REF, AP, MR, PR, respectively). Thus, 501 cows were included in the final analyses.

Table 1 presents descriptive data for clinical and reproductive performance measures for the 4 treatment groups considering cows with and without fever. The descriptive data of clinical and reproductive performance for herd is shown in Table 2. In the logistic regression models shown in Table 3 , for the risk of receiving an escape therapy, herd 4 was chosen as reference for covariate "herd", because it showed the lowest proportion $(7.7 \%)$ of cows with an escape therapy (Table 2). For the risk of conceiving after first service, herd 1 was chosen as reference herd, because it achieved the highest first-service conception rate $(37.3 \%$; Table 2). Results of the survival analyses are shown in Table 4. In the survival analysis for the outcome fever, herd 1 was chosen as reference for the covariate "herd" because herd 1 had the lowest proportion of cows with fever within $10 \mathrm{~d}$ PP (65.5\%; Table 2). For survival analyses on insemination, pregnancy, and culling within $200 \mathrm{~d}$ $\mathrm{PP}$, herd 2 was chosen as reference, because this herd showed the numerically highest proportion of cows inseminated $(91.9 \%)$ and pregnant $(67.7 \%)$, and the lowest proportion of cows culled (9.1\%; Table 2).

\section{Treatment Groups}

Possible interactions of treatment group and herd as well as interactions of treatment group and parity on 
Table 1. Description of clinical and reproductive performance variables in treatment groups REF, AP, MR, and PR ${ }^{1}$

\begin{tabular}{|c|c|c|c|c|c|}
\hline \multirow[b]{2}{*}{ Variable } & \multirow[b]{2}{*}{ Fever } & \multicolumn{4}{|c|}{ Treatment group } \\
\hline & & $\operatorname{REF}(\mathrm{n}=131)$ & $\mathrm{AP}(\mathrm{n}=119)$ & $\mathrm{MR}(\mathrm{n}=121)$ & $\mathrm{PR}(\mathrm{n}=130)$ \\
\hline Proportion of cows (\%) & $\begin{array}{l}\text { Yes } \\
\text { No }\end{array}$ & $\begin{array}{l}85.5 \\
14.5\end{array}$ & $\begin{array}{l}78.2 \\
21.8\end{array}$ & $\begin{array}{l}84.3 \\
15.7\end{array}$ & $\begin{array}{l}71.5 \\
28.5\end{array}$ \\
\hline Escape therapy $^{2}(\%)$ & $\begin{array}{l}\text { Yes } \\
\text { No } \\
\text { Total }\end{array}$ & $\begin{array}{r}18.8 \\
0.0 \\
16.0\end{array}$ & $\begin{array}{r}11.8 \\
0.0 \\
9.2\end{array}$ & $\begin{array}{r}15.7 \\
0.0 \\
13.2\end{array}$ & $\begin{array}{r}10.8 \\
0.0 \\
7.7\end{array}$ \\
\hline $\begin{array}{l}\text { Days to first service } \\
\text { (median, quartiles) }\end{array}$ & $\begin{array}{l}\text { Yes } \\
\text { No } \\
\text { Total }\end{array}$ & $\begin{array}{ll}71.5 & (60.0-92.0) \\
61.0 & (49.0-69.0) \\
77.0 & (61.0-106.0)\end{array}$ & $\begin{array}{ll}74.0 & (63.75-93.0) \\
71.5 & (63.25-80.75) \\
74.0 & (63.75-92.25)\end{array}$ & $\begin{array}{ll}74.0 & (64.0-93.0) \\
75.5 & (67.25-86.5) \\
75.5 & (64.5-92.0)\end{array}$ & $\begin{array}{ll}75.0 & (61.0-91.0) \\
76.0 & (63.5-91.0) \\
75.0 & (62.25-91.0)\end{array}$ \\
\hline First-service conception rate $(\%)$ & $\begin{array}{l}\text { Yes } \\
\text { No } \\
\text { Total }\end{array}$ & $\begin{array}{l}33.3 \\
28.6 \\
32.7\end{array}$ & $\begin{array}{l}34.6 \\
25.0 \\
32.7\end{array}$ & $\begin{array}{l}38.6 \\
21.4 \\
36.1\end{array}$ & $\begin{array}{l}31.0 \\
12.1 \\
25.0\end{array}$ \\
\hline $\begin{array}{l}\text { Days to pregnancy } \\
\text { (median, quartiles) }\end{array}$ & $\begin{array}{l}\text { Yes } \\
\text { No } \\
\text { Total }\end{array}$ & $\begin{array}{rr}104.5 & (70.0-147.0) \\
91.0 & (62.0-122.5) \\
97.5 & (70.0-138.0)\end{array}$ & $\begin{array}{ll}100.5 & (73.25-141.5) \\
112.0 & (99.0-161.0) \\
104.0 & (75.0-143.0)\end{array}$ & $\begin{array}{rr}92.0 & (73.5-132.0) \\
112.0 & (89.5-129.5) \\
93.0 & (75.0-132.0)\end{array}$ & $\begin{aligned} 94.5 & (79.0-136.25) \\
121.0 & (89.5-159.0) \\
99.5 & (80.25-136.75)\end{aligned}$ \\
\hline Cows pregnant within $200 \mathrm{~d} \mathrm{PP}^{3}(\%)$ & $\begin{array}{l}\text { Yes } \\
\text { No } \\
\text { Total }\end{array}$ & $\begin{array}{l}60.7 \\
63.2 \\
61.1\end{array}$ & $\begin{array}{l}64.5 \\
65.4 \\
64.7\end{array}$ & $\begin{array}{l}59.8 \\
52.6 \\
58.7\end{array}$ & $\begin{array}{l}53.8 \\
48.6 \\
52.3\end{array}$ \\
\hline Cows culled within 200 d PP (\%) & $\begin{array}{l}\text { Yes } \\
\text { No } \\
\text { Total }\end{array}$ & $\begin{array}{l}14.3 \\
26.3 \\
16.0\end{array}$ & $\begin{array}{l}18.3 \\
30.8 \\
21.0\end{array}$ & $\begin{array}{l}15.7 \\
36.8 \\
19.0\end{array}$ & $\begin{array}{l}23.7 \\
13.5 \\
20.8\end{array}$ \\
\hline
\end{tabular}

${ }^{1}$ Treatment groups: $\mathrm{REF}=$ reference group; cows with fever received systemic antibiotic, ceftiofur; $\mathrm{AP}=$ antibiotic pills in uterus of all cows; cows with fever treated as in REF; MR = manual removal of retained fetal membrane for all cows; cows with fever treated as in REF; $\mathrm{PR}=$ antibiotic pills in uterus plus manual removal of retained fetal membranes; cows with fever treated as in REF.

${ }^{2}$ Cows with fever after a maximum of 5 treatments with ceftiofur.

${ }^{3} \mathrm{PP}=$ Postpartum.

the outcome variables were tested but were not significant $(P>0.05)$. Survival analysis revealed that hazard of fever within $10 \mathrm{~d}$ PP was significantly lower $(P<$ 0.05) in groups $\mathrm{AP}$ and $\mathrm{PR}$ compared with group REF
(Table 4). Figure 1 presents the cumulative proportion of cows with fever within the first $10 \mathrm{~d}$ PP. The risk for receiving an escape therapy after a maximum of 5 treatments with ceftiofur was not significantly affected

Table 2. Descriptive data of clinical and reproductive performance variables for herds 1 to 5

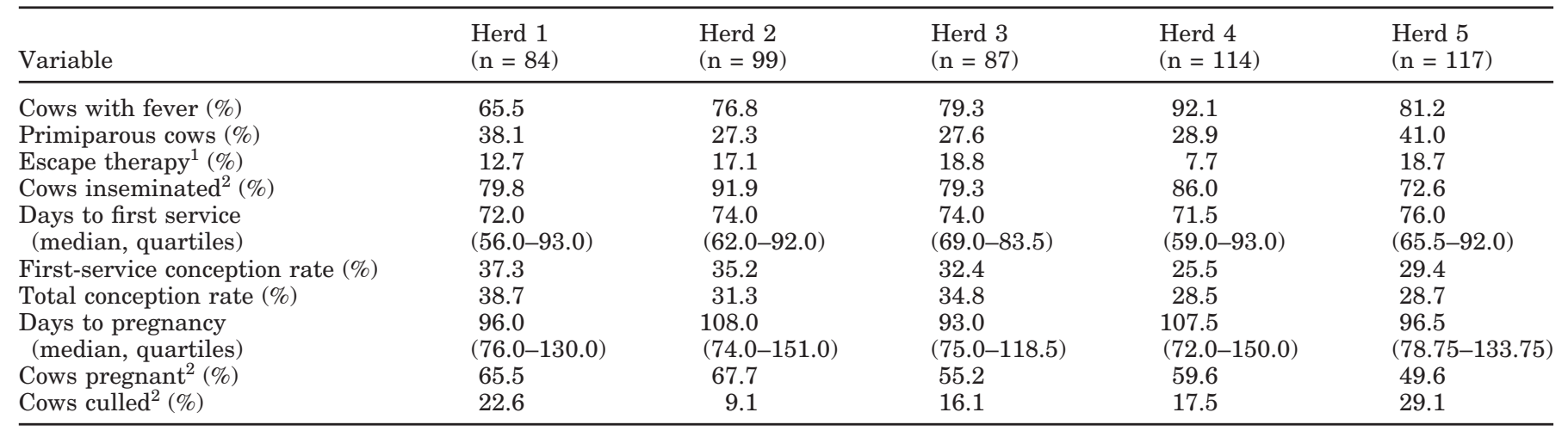

${ }^{1}$ Cows with fever after a maximum of 5 treatments with ceftiofur received additional antibiotic therapy via recommendation of herd veterinarian.

${ }^{2}$ Within 200 d postpartum. 
Table 3. Results of the logistic regression models for the risk of receiving an escape therapy (for cows with fever) and the risk of conceiving after first service, including group, herd, fever, and parity as covariates

\begin{tabular}{|c|c|c|c|c|c|c|c|}
\hline \multirow[b]{2}{*}{ Factor } & \multirow[b]{2}{*}{ df } & \multicolumn{3}{|c|}{ Escape therapy $^{2}$} & \multicolumn{3}{|c|}{ Conceiving after first service ${ }^{3}$} \\
\hline & & $\mathrm{OR}^{4}$ & $95 \% \mathrm{CI}^{4}$ & $P$-value & OR & $95 \% \mathrm{CI}$ & $P$-value \\
\hline Group $^{1}$ & 3 & & & 0.43 & & & 0.59 \\
\hline $\mathrm{REF}^{1}$ & 1 & & Reference group & & & Reference group & \\
\hline $\mathrm{AP}^{1}$ & 1 & 0.60 & $0.27-1.33$ & 0.21 & 1.09 & $0.60-1.97$ & 0.78 \\
\hline $\mathrm{MR}^{1}$ & 1 & 0.88 & $0.43-1.82$ & 0.73 & 1.23 & $0.68-2.20$ & 0.49 \\
\hline $\mathrm{PR}^{1}$ & 1 & 0.57 & $0.25-1.30$ & 0.18 & 0.80 & $0.43-1.48$ & 0.47 \\
\hline Herd & 4 & & & 0.20 & & & 0.20 \\
\hline Herd 1 & 1 & 1.60 & $0.54-4.71$ & 0.40 & & Reference herd & \\
\hline Herd 2 & 1 & 2.41 & $0.94-6.18$ & 0.07 & 0.84 & $0.43-1.66$ & 0.61 \\
\hline Herd 3 & 1 & 2.83 & $1.10-7.31$ & 0.03 & 0.74 & $0.35-1.54$ & 0.42 \\
\hline Herd 4 & 1 & & Reference herd & & 0.46 & $0.23-0.93$ & 0.03 \\
\hline Herd 5 & 1 & 2.48 & $1.00-6.15$ & 0.05 & 0.59 & $0.29-1.19$ & 0.14 \\
\hline Fever $^{5}$ & 1 & - & - & - & 2.27 & $1.21-4.26$ & 0.01 \\
\hline Parity class ${ }^{6}$ & 1 & 1.77 & $0.98-3.16$ & 0.06 & 1.28 & $0.82-2.01$ & 0.28 \\
\hline Constant & & 0.14 & & $<0.01$ & & & $<0.01$ \\
\hline
\end{tabular}

${ }^{1}$ Treatment groups: $\mathrm{REF}$ = reference group; cows with fever received systemic antibiotic, ceftiofur; $\mathrm{AP}=$ antibiotic pills in uterus of all cows; cows with fever treated as in REF; MR = manual removal of retained fetal membrane for all cows; cows with fever treated as in REF; PR = antibiotic pills in uterus plus manual removal of retained fetal membranes; cows with fever treated as in REF.

${ }^{2}$ Escape therapy: $0=$ no escape therapy, 1 = escape therapy.

${ }^{3}$ Conceiving after first service: $0=$ not conceived after first service, $1=$ conceived after first service.

${ }^{4} \mathrm{OR}=$ Odds ratio; $\mathrm{CI}=$ confidence interval.

${ }^{5}$ Fever: $0=$ no fever, $1=$ fever. No fever was the reference group.

${ }^{6}$ Parity: 0 = multiparous, 1 = primiparous. Primaparous was the reference group.

by treatment group (Table 3). The logistic regression model for the risk of conceiving after first service (Table 3 ) and survival analyses for the hazards of insemination, pregnancy, and culling within $200 \mathrm{~d}$ PP, respectively, indicated that those variables were not significantly affected by treatment group (Table 4).
Cows with Fever. Of all animals included in the study, $79.8 \%$ had a body temperature of $39.5^{\circ} \mathrm{C}$ or above at least once within $10 \mathrm{~d} \mathrm{PP}$ and were treated with ceftiofur. Cows with fever within $10 \mathrm{~d}$ PP were more likely $(P<0.05)$ to conceive after first service than cows without fever (Table 3). None of the variables tested

Table 4. Results of the survival analyses (Cox-Regression) for the hazard of fever within $10 \mathrm{~d}$ postpartum, and the hazards of insemination, pregnancy, and culling within $200 \mathrm{~d}$ postpartum, including group, herd, fever, and parity as covariates

\begin{tabular}{|c|c|c|c|c|c|c|c|c|c|c|c|c|c|}
\hline Factor & $\mathrm{df}$ & \multicolumn{3}{|c|}{ Fever } & \multicolumn{3}{|c|}{ Insemination } & \multicolumn{3}{|c|}{ Pregnancy } & \multicolumn{3}{|c|}{ Culling } \\
\hline Group $^{1}$ & 3 & \multicolumn{3}{|c|}{ Reference group $<0.01$} & \multicolumn{3}{|c|}{ Reference group } & & & 0.39 & & & 0.77 \\
\hline $\mathrm{AP}$ & 1 & 0.70 & $0.53-0.92$ & 0.01 & 0.84 & $0.64-1.10$ & 0.21 & 1.07 & $0.78-1.47$ & 0.68 & 1.37 & $0.76-2.46$ & 0.29 \\
\hline MR & 1 & 1.05 & $0.80-1.38$ & 0.71 & 0.84 & $0.64-1.11$ & 0.22 & 0.97 & $0.70-1.33$ & 0.83 & 1.15 & $0.64-2.08$ & 0.64 \\
\hline PR & 1 & 0.71 & $0.54-0.94$ & 0.02 & 0.88 & $0.68-1.16$ & 0.37 & 0.81 & $0.58-1.12$ & 0.20 & 1.19 & $0.67-2.12$ & 0.55 \\
\hline Herd 2 & 1 & 1.51 & $1.06-2.14$ & 0.02 & \multicolumn{3}{|c|}{ Reference herd } & \multicolumn{3}{|c|}{ Reference herd } & \multicolumn{3}{|c|}{ Reference herd } \\
\hline Herd 3 & 1 & 1.37 & $0.96-1.96$ & 0.08 & 0.72 & $0.53-0.99$ & 0.04 & 0.83 & $0.57-1.20$ & 0.32 & 1.89 & $0.81-4.37$ & 0.14 \\
\hline Herd 4 & 1 & 2.10 & $1.51-2.92$ & $<0.01$ & 0.91 & $0.68-1.21$ & 0.51 & 0.83 & $0.59-1.16$ & 0.27 & 2.12 & $0.96-4.70$ & 0.06 \\
\hline Herd 5 & 1 & 1.83 & $1.31-2.56$ & $<0.01$ & 0.58 & $0.43-0.78$ & $<0.01$ & 0.63 & $0.44-0.89$ & 0.01 & 4.04 & $1.93-8.45$ & $<0.01$ \\
\hline Fever $^{3}$ & 1 & - & - & - & 0.84 & $0.65-1.08$ & 0.18 & 1.02 & $0.75-1.39$ & 0.90 & 0.80 & $0.49-1.30$ & 0.37 \\
\hline Parity $^{4}$ & 1 & 1.71 & $1.39-2.11$ & $<0.01$ & 1.365 & $1.10-1.69$ & $<0.01$ & 1.42 & $1.11-1.82$ & 0.01 & 0.54 & $0.33-0.88$ & 0.01 \\
\hline
\end{tabular}

${ }^{1}$ Treatment groups: REF = reference group; cows with fever received systemic antibiotic, ceftiofur; $\mathrm{AP}=$ antibiotic pills in uterus of all cows; cows with fever treated as in REF; MR = manual removal of retained fetal membrane for all cows; cows with fever treated as in REF; $\mathrm{PR}=$ antibiotic pills in uterus plus manual removal of retained fetal membranes; cows with fever treated as in REF.

${ }^{2} \mathrm{HR}=$ Hazard ratio; $\mathrm{CI}=$ confidence interval.

${ }^{3}$ Fever: $0=$ no fever, $1=$ fever. No fever was the reference group.

${ }^{4}$ Parity: 0 = multiparous, 1 = primiparous. Primaparous was the reference group. 


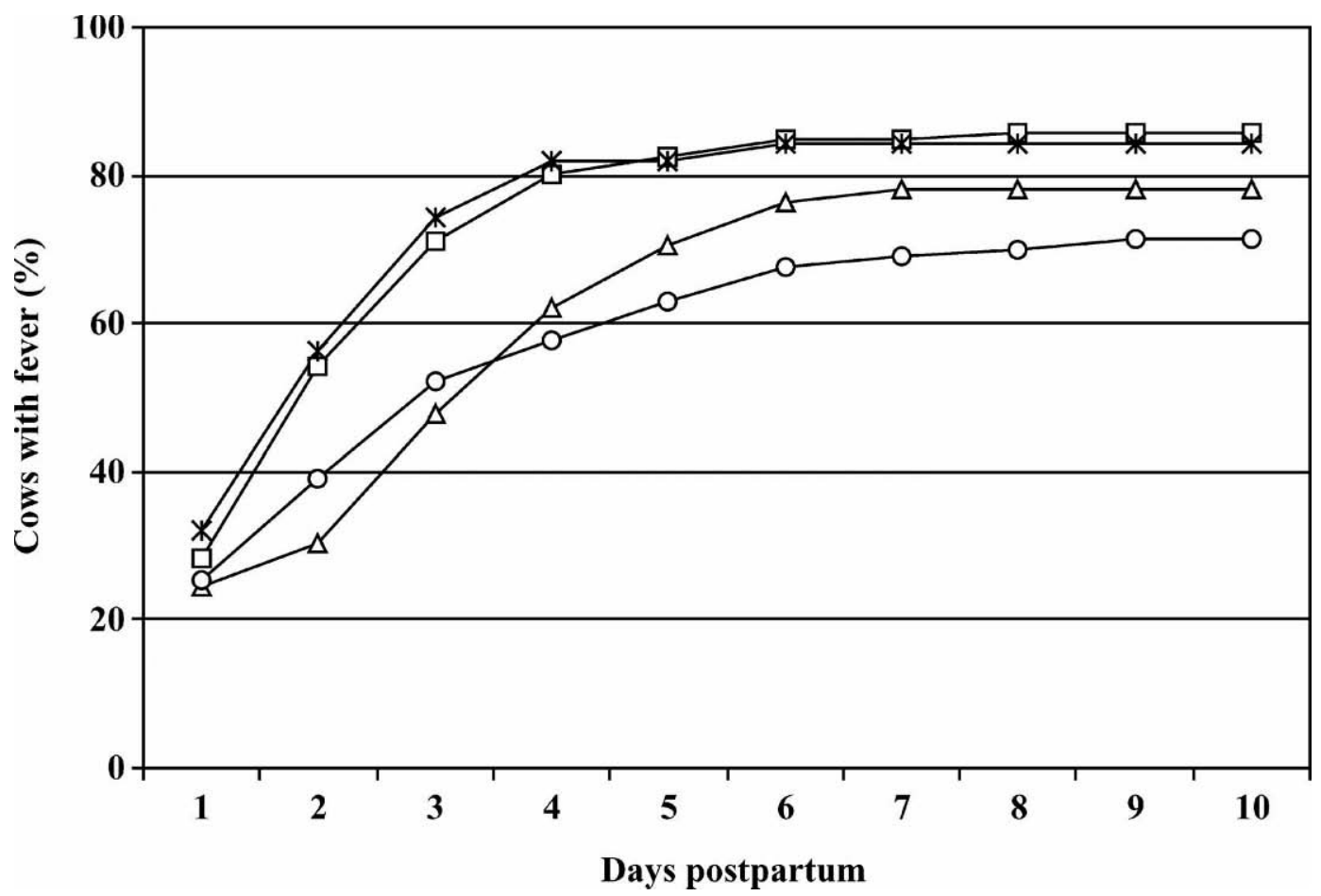

Figure 1. Cumulative proportions of cows having retained fetal membranes with at least $1 \mathrm{~d}$ of fever $\left(\geq 39.5^{\circ} \mathrm{C}\right)$ within $10 \mathrm{~d}$ postpartum including a reference group without any intrauterine therapy (REF, $\square$ ), a group receiving intrauterine use of antibiotic pills (AP, $\triangle$ ), a group with manual removal of the fetal membranes (MR, *), or a group receiving both AP and MR (PR, O). Regardless of group, cows with a fever received systemic antibiotic for 3 to $5 \mathrm{~d}$.

by survival analyses was significantly affected by the occurrence of fever (Table 4).

\section{Herd}

Logistic regression models showed that the risk for receiving an escape therapy as well as the risk for conceiving after first service was not significantly influenced by the covariate "herd" (Table 3). However, the risk for receiving an escape therapy was significantly higher in herd $3(P<0.05)$, and the risk for conceiving after first service was significantly higher in herd $4(P$ $<0.05)$ compared with the reference herds (Table 3). Significant effects of the covariate "herd" $(P<0.05)$ were detected for all outcomes calculated in the survival analyses; that is, hazards of fever within $10 \mathrm{~d}$ PP, insemination, pregnancy, and culling within $200 \mathrm{~d}$ PP (Table 4).

Parity. Among primiparous cows with a retained placenta, $90.9 \%$ had a fever within $10 \mathrm{~d}$ PP, whereas, of multiparous cows, only $75.4 \%$ had a fever. Survival analysis indicated that primiparous cows had a significantly higher hazard of fever within $10 \mathrm{~d}$ PP than multiparous cows $(P<0.01$; Table 4$)$. In the logistic regression model, there was a tendency $(P=0.06)$ for primipa- rous cows to be at higher risk for receiving an escape therapy than multiparous cows (Table 3). Survival analyses showed that hazards of insemination and pregnancy within $200 \mathrm{~d}$ PP were significantly higher in primiparous than in multiparous cows $(P<0.05)$. Primiparous cows were less likely to be culled than multiparous cows $(P<0.05$, Table 4$)$.

\section{Number of Antibiotic Treatments}

Total antibiotic treatments per group, including systemic and local treatments as well as escape therapies, are shown in Table 5. For the calculation, the escape therapy (chosen by the local veterinarians) was considered to consist of 3 antibiotic treatments. Numerically, the number of antibiotic treatments was higher in groups AP and PR, in which antibiotic pills were administered to all cows, than in groups REF and MR, in which only cows experiencing a fever received antibiotics.

\section{DISCUSSION}

The local antibiotic treatment and the manual removal as a treatment of retained fetal membranes in 
Table 5. Total number of systemic and local antibiotic treatments and escape therapies applied, and treatments per cow in the groups REF, AP, MR, and $\mathrm{PR}^{1}$

\begin{tabular}{|c|c|c|c|c|}
\hline \multirow[b]{2}{*}{ Treatment } & \multicolumn{4}{|c|}{ Treatment group } \\
\hline & $\begin{array}{l}\text { REF } \\
(n=131)\end{array}$ & $\begin{array}{l}\mathrm{AP} \\
(\mathrm{n}=119)\end{array}$ & $\begin{array}{l}\mathrm{MR} \\
(\mathrm{n}=121)\end{array}$ & $\begin{array}{l}\mathrm{PR} \\
(\mathrm{n}=130)\end{array}$ \\
\hline Systemic treatment ${ }^{2}$ & 457 & 367 & 412 & 360 \\
\hline Intrauterine treatment ${ }^{3}$ & 0 & 357 & 0 & 390 \\
\hline Escape therapy ${ }^{4}$ & 63 & 33 & 48 & 30 \\
\hline Total & 520 & 757 & 460 & 780 \\
\hline \multicolumn{5}{|l|}{ Treatments per cow } \\
\hline First quartile & 3.0 & 6.0 & 3.0 & 3.0 \\
\hline Median & 3.0 & 6.0 & 3.0 & 6.0 \\
\hline Third quartile & 5.0 & 8.0 & 5.0 & 8.0 \\
\hline
\end{tabular}

${ }^{1}$ Treatment groups: $\mathrm{REF}=$ reference group; cows with fever received systemic antibiotic, ceftiofur; $\mathrm{AP}=$ antibiotic pills in uterus of all cows; cows with fever treated as in REF; MR = manual removal of retained fetal membrane for all cows; cows with fever treated as in REF; PR = antibiotic pills in uterus plus manual removal of retained fetal membranes; cows with fever treated as in REF.

${ }^{2}$ One treatment $=1 \mathrm{mg}$ of ceftiofur $/ \mathrm{kg}$ of $\mathrm{BW}$. Individual cows with rectal temperatures $\geq 39.5^{\circ} \mathrm{C}$ each received 3 to 5 daily treatments.

${ }^{3}$ One treatment $=2$ uterine pills consisting of $1,000 \mathrm{mg}$ of ampicillin and 1,000 $\mathrm{mg}$ of cloxacillin and each cow in those groups received a treatment on 3 consecutive days.

${ }^{4}$ The escape therapy was considered to consist of 3 antibiotic treatments.

dairy cows has been an issue of controversy in the literature as well as in veterinary practice for many years (Paisley et al., 1986; Bolinder et al., 1988; Drillich et al., 2003). The trial described herein is one of the largest prospective, controlled field studies on the efficacy of different treatment protocols for retained fetal membranes published in many years. People making decisions about inseminations, culling, and so on, should have been unaware of the assignments of cows to treatment groups. However, practical considerations with respect to logistical problems led to a study design that was not blinded.

The incidence of fever within the first $10 \mathrm{~d}$ PP was relatively high in all herds in this trial compared with the results of other authors (Stevens et al., 1995; Dinsmore et al., 1996). However, in previous field studies on large dairy farms in Germany, the incidence of fever in cows with RFM was similar (Drillich et al., 2003, 2005). Fever as a sign of systemic illness indicates that the retention of the fetal membranes is often associated with acute metritis (Correa et al., 1993; Laven and Peters, 1996). The current results showed that the proportions of cows with fever were higher in groups REF and MR (that did not receive intrauterine antibiotic pills) in contrast to groups $\mathrm{AP}$ and $\mathrm{PR}$, in which all cows received antibiotic pills. However, the local administration of antibiotics was not effective to prevent fever in all cows. More than $70 \%$ of the cows developed a fever even though they received local antibiotics. Moreover, in most of the cows in groups MR and PR, manual removal of the fetal membranes did not prevent fever. In addition, there was large variability among herds, indicating that herd-specific factors, such as hygiene or bacterial flora, play an important role in the occurrence of fever. It was not the aim of the study to clarify the exact origin(s) of fever. Because there was no control group of cows with untreated fevers, it remains unclear if the reduced number of cows with fever after treatment with ceftiofur was a result of the antibiotic treatment or a consequence of a spontaneous cure. The proportion of cows requiring an escape therapy after 5 treatments with ceftiofur was not affected by treatment group.

With regard to reproductive performance variables, no statistically significant differences were found between the reference group and the other 3 groups. This indicates that neither the application of uterine pills nor the manual removal of the fetal membranes or the combination improved reproductive performance compared with group REF. This is in accordance with the results of an earlier study (Drillich et al., 2003) that compared 2 treatment groups similar to groups REF and PR of this trial, although the number of cows in that study was only 35 in each group. Bolinder et al. (1988) even found a negative impact of a manual detachment of the fetal membranes but such a detrimental effect was not observed in the current study.

There was a pattern of lower values for first-service conception rates, total conception rates, and proportion of cows pregnant by $200 \mathrm{~d}$ PP in group PR (Table 2), although these results were not significantly different from group REF. This might indicate that the combination of both uterine manipulations (group PR) had a negative impact on reproductive performance, whereas 
each manipulation by itself (groups AP and MR) did not result in such an effect. One hypothesis for this observation could be that the manual removal as well as local application of antibiotics impairs uterine defense mechanism only marginally, whereas the combination of both manipulations has a more pronounced negative effect (Paisley et al., 1986).

Because of the study design, it was expected that the largest amounts of antibiotic drugs would be used in groups AP and PR. Even though proportions of escape therapies applied in groups REF and MR were numerically higher than in groups AP and PR, the total number of antibiotic treatments per cow was lower in groups $\mathrm{REF}$ and MR. The selective systemic antibiotic treatment of cows with RFM only in case of fever can support efforts to reduce the amount of antibiotic drugs used in food-producing animals. Further, the subcutaneous administration provides concentrations of ceftiofur in uterine tissues and lochial fluids that exceed MIC values for common uterine pathogens (Okker et al., 2002). Both a selective treatment and a reliable route of administration are in accordance with the recommendation of the World Health Organization for the prudent use of antibiotic drugs to prevent antimicrobial resistance (WHO, 1997).

Logistic regression revealed that the risk of conceiving after first service was affected by the occurrence of fever within the first $10 \mathrm{~d}$ PP. Surprisingly, the risk of conceiving after the first service was significantly higher for cows with fever within $10 \mathrm{~d}$ PP than for cows without fever. It remains speculative if this result is the effect of the antibiotic therapy for cows with fever. This treatment might have supported a bacteriologically negative status of the uterus at the day of first service. An alternative explanation is that fever itself indicates the reaction of the immune system against the inflammatory noxa and therefore can be regarded as a sign for an intact immune response (Laroux, 2004). However, this observation was not confirmed by statistically significant differences for any other measure of reproductive performance. Additionally, the unbalanced number of cows with and without fever might bias the results.

The occurrence of fever as well as efficacy of therapy as measured by the number of escape therapies applied was influenced by parity. A higher incidence of acute metritis in primiparous cows has also been described by Markusfeld (1987). It is well known that heifers have a higher incidence of dystocia (Dematawewa and Berger, 1997), which is a risk factor for acute metritis. Because calvings were monitored by several individuals on the farms without a standardized definition of "dystocia," we did not analyze the proportion of dystocia for primiparous and multiparous cows. Primiparous cows had significantly higher hazards for insemination and pregnancy within $200 \mathrm{~d}$ PP and a lower risk for being culled than multiparous cows. This is in line with a number of recent publications on better reproductive performance in primiparous than in older cows (Cartmill et al., 2001; Tenhagen et al., 2004).

Respective proportions of cows inseminated, pregnant, and culled were significantly influenced by herd, indicating a strong influence of management factors on reproductive performance.

\section{CONCLUSIONS}

This large-scale field trial demonstrated that neither local antibiotic treatment nor manual removal of the retained placenta or the combination of both resulted in an improved clinical efficacy or reproductive performance compared with an exclusive systemic antibiotic treatment of cows experiencing fever. Only the incidence of fever within $10 \mathrm{~d}$ PP was reduced by local antibiotics. Clinical and reproductive performance variables were influenced by herd and parity. The treatment of cows with RFM with antibiotics only in case of fever and the selective use of systemic rather than local antibiotics were efficacious and this is consistent with the principles of prudent use of antibiotics in cattle.

\section{ACKNOWLEDGMENTS}

The authors gratefully acknowledge the support of the study by Pfizer Animal Health USA and Pfizer Animal Health Germany and the cooperation with the staff of the farms and local veterinarians.

\section{REFERENCES}

Bolinder, A., B. Seguin, H. Kindahl, D. Bouley, and D. Otterby. 1988. Retained fetal membranes in cows: Manual removal versus nonremoval and its effect on reproductive performance. Theriogenology $30: 45-56$.

Cartmill, J. A., S. Z. El-Zarkouny, B. A. Hensley, G. C. Lamb, and J. S. Stevenson. 2001. Stage of cycle, incidence, and timing of ovulation, and pregnancy rates in dairy cattle after three timed breeding protocols. J. Dairy Sci. 84:1051-1059.

Chenault, J. R., J. F. McAllister, S. T. Chester, K. J. Dame, F. M. Kausche, and E. J. Robb. 2004. Efficacy of ceftiofur hydrochloride sterile suspension administered parenterally for the treatment of acute postpartum metritis in dairy cows. J. Am. Vet. Med. Assoc. 224:1634-1639.

Correa, M. T., H. Erb, and J. Scarlett. 1993. Path analysis for seven postpartum disorders of Holstein cows. J. Dairy Sci. 76:13051312 .

Dematawewa, C. M. B., and P. J. Berger. 1997. Effect of dystocia on yield, fertility, and cow losses and economic evaluation of dystocia scores for Holsteins. J. Dairy Sci. 80:754-761.

Dinsmore, R. P., R. D. Stevens, M. B. Cattell, M. D. Salman, and S. F. Sundlof. 1996. Oxytetracycline residues in milk after intrauterine treatment of cows with retained fetal membranes. J. Am. Vet. Med. Assoc. 209:1753-1755.

Drillich, M., O. Beetz, A. Pfützner, M. Sabin, H.-J. Sabin, P. Kutzer, H. Nattermann, and W. Heuwieser. 2001. Evaluation of a systemic 
antibiotic treatment of toxic puerperal metritis in dairy cows. J. Dairy Sci. 84:2010-2017.

Drillich, M., A. Pfützner, H.-J. Sabin, M. Sabin, and W. Heuwieser. 2003. Comparison of two protocols for the treatment of retained fetal membranes in dairy cattle. Theriogenology 59:951-960.

Drillich, M., A. Schröder, B.-A. Tenhagen, and W. Heuwieser. 2005. Wirksamkeit einer Behandlung der Retentio secundinarum beim Rind mit Prostaglandin $\mathrm{F}_{2 \alpha}$ in Ergänzung zu einer lokalen Antibiose. Dtsch. Tieraerztl. Wochenschr. 12:174-179.

Dyrendahl, I., J. Mattson, and B. Rehrson. 1977. Retained placenta in cattle-incidence, clinical data and effects on fertility. Zbl. Vet. Med. A 24:529-541.

Eiler, H. 1997. Retained placenta. Pages 340-348 in Current Therapy in Large Animal Theriogenology. R. S. Youngquist, ed. W. B. Saunders Company, Philadelphia, PA.

Fourichon, C., H. Seegers, and X. Malher. 2000. Effect of disease on reproduction in the dairy cow: A meta-analysis. Theriogenology 53:1729-1759.

Gröhn, Y. T., and P. J. Rajala-Schultz. 2000. Epidemiology of reproductive performance in dairy cows. Anim. Reprod. Sci. 6061:605-614.

Laroux, F. S. 2004. Mechanisms of inflammation: The good, the bad and the ugly. Front. Biosci. 9:3156-3162.

Laven, R. A. 1995. The treatment of retained placenta. A survey of practitioners. Cattle Pract. 3:267-279.

Laven, R. A., and A. R. Peters. 1996. Bovine retained placenta: Aetiology, pathogenesis and economic loss. Vet. Rec. 139:465-471.

Markusfeld, O. 1987. Periparturient traits in seven high dairy herds. Incidence rates, association with parity, and interrelationship among traits. J. Dairy Sci. 70:158-168.

Okker, H., E. J. Schmitt, P. L. A. M. Vos, P. Scherpenisse, A. A. Bergwerff, and F. H. Jonker. 2002. Pharmacokinetics of ceftiofur in plasma and uterine secretions and tissues after subcutaneous postpartum administration in lactating dairy cows. J. Vet. Pharmacol. Therap. 25:33-38,
Paisley, L. G., W. D. Mickelsen, and P. B. Anderson. 1986. Mechanism and therapy for retained fetal membranes and uterine infections of cows: A review. Theriogenology 25:353-381.

Peters, A. R., and R. A. Laven. 1996. Treatment of bovine retained placenta and its effects. Vet. Rec. 139:535-539.

Risco, C. A., and J. Hernandez. 2003. Comparison of ceftiofur hydrochloride and estradiol cypionate for metritis prevention in dairy cows affected with retained fetal membranes. Theriogenology 60:47-58.

Sheldon, I. M., M. Bushnell, J. Montgomery, and A. N. Rycroft. 2004. Minimum inhibitory concentrations of some anti microbial drugs against bacteria causing uterine infections in cattle. Vet. Rec. 15:383-387.

Sheldon, I. M., and H. Dobson. 2004. Postpartum uterine health in cattle. Anim. Reprod. Sci. 82-83:295-306.

Smith, B. I., G. A. Donovan, C. Risco, R. Littell, C. Young, L. H. Stanker, and J. Elliott. 1998. Comparison of various antibiotic treatments for cows diagnosed with toxic puerperal metritis. J. Dairy Sci. 81:1555-1562.

Stevens, R. D., R. P. Dinsmore, and M. B. Cattell. 1995. Evaluation of the use of intrauterine infusion of oxytetracycline, subcutaneous injections of fenprostalene, or a combination of both, for the treatment of retained fetal membranes in dairy cows. J. Am. Vet. Med. Assoc. 207:1612-1615.

Tenhagen, B.-A., R. Surholt, M. Wittke, C. Vogel, M. Drillich, and W. Heuwieser. 2004. Use of Ovsynch in dairy herds-differences between primiparous and multiparous cows. Anim. Reprod. Sci. $81: 1-11$

World Health Organization. 1997. Recommendations in WHO Proceedings: The medical impact of the use of antimicrobials in food animals. WHO/EMC/ZOO/97 4:11-16.

Zhou, C., J. F. Boucher, K. J. Dame, M. Moreira, R. Graham, J. Nantel, S. Zuidhof, L. Arfi, R. Flores, G. Neubauer, and J. Olson. 2001. Multilocation trial of ceftiofur for treatment of postpartum cows with fever. J. Am. Vet. Med. Assoc. 219:805-808. 